\title{
A Comparative Study of Infant And Young Child Feeding Practices In one District Each in Punjab And Haryana States of Northern India: How Much We Have Improved in Last Decade?
}

\author{
${ }^{1}$ Dr.Sumeet Singh, ${ }^{2}$ Dr. Sumitgoyat,${ }^{3}$ Dr.Gurjinder Singh \\ ${ }^{I}$ Senior Resident, Dept. Of Community Medicine, Government Medical College, Patiala And Member Of IYCF \\ Counselling Specialists Group Of Breast Feeding Promotion Network Of India (BPNI) \\ 29/1, Lahori Gate, TB Hospital Road, Nr. Malhotra Ultrasound, Patiala
}

\begin{abstract}
Introduction: Early and Exclusive breastfeeding $(E B F)$ along with appropriate complementary feeding has now been well recognised as one of the most effective interventions for child survival particularly to address morbidity and mortality. In India 20 million babies don't receive EBF.

Aims \& Objectives: To assess and compare the present scenario and trends of awareness and practices of IYCF among mothers in Haryana and Punjab.

Methodology: It was a cross sectional study conducted at state health institutions in Barnala and Kaithal. A standardized, structured, pretested, closed ended questionnaire was used for face-to-face interview mothers of child below 2 years.

Results: In group A and B, $38.89 \%$ and 61.67\% of the respondents respectively were aware of initiation of breastfeeding in 1 st hour of birth but only half practice. EBF rates for 0-6 months were found to be $39.44 \%$ \& 37.78 $\%$ in 2 districts. Only around $20 \%$ mothers had continued breastfeeding beyond 18 months. $47 \%$ mothers in Kaithal and 60\% mothers in Barnala stated that they had not been formally counselled, guided or advised by anyone. Discussion: Barnala scored better than Kaithal and NFHS figures in early initiation.Rates of exclusive breastfeeding were found to be lower in both districts thannational figures of NFHS-3 in 2005-06.Around 60\% of mothers in both the groups had started mix feeding in first 6 months.

Conclusion: Although both the states are working on the training of health workers to adopt and spread IYCF practices, but still the performance seems to be even below the national figures shown in NFHS -3.
\end{abstract}

Keywords: IYCF, Breastfeeding, Infant feeding, feeding practices

\section{Introduction}

Early and Exclusive breastfeeding (EBF) along with appropriate complementary feeding has now been well recognised as one of the most effective interventions for child survival particularly to address morbidity and mortality related to three major problems i.e. neonatal infections, diarrhoea and pneumonia ${ }^{1}$. It has nutritional, economical, behavioural, psychosocial and immunological benefits ${ }^{2}$. While breastfeeding provides optimal nutrition to an infant, improvements in complementary feeding substantially reduces stunting and related burden of disease ${ }^{1}$. According to the WHO's 2002 Global Strategy for Infant and Young Child Feeding, Malnutrition has been responsible, directly or indirectly, for 60 per cent of the 10.9 million deaths annually among children under five. While in India also undernutrition is a contributory factor in one third to half of all deaths taking place in children under five years of age. $43 \%$ children in India under five years are reported to be underweight and $48 \%$ are stunted (NFHS-3; 2005-06). Onset of malnutrition occurs in the very early years of growth andincreases rapidly from birth to age 20-23 months ${ }^{1}$. It is estimated that exclusive breastfeeding prevents $13 \%$ of the estimated under-five deaths while appropriate complementary feeding prevents another $6 \%$ of under-five deaths and help the children to reach their full growth potential ${ }^{1}$. Annually about 26 million babies are delivered in India. According to National Family Health Survey (NFHS) -3, 2005-06 data, 20 million babies are not able to receive exclusive breastfeeding for the first six months and about 13 million do not get good timely and appropriate complementary feeding after six months along with continued breastfeeding ${ }^{3}$. Unfortunately, exclusive breastfeeding for the first six months has not shown any rise over the past two decades since India began measuring them. Only $25 \%$ of new-borns were put to the breast within one hour of birth. Less than half of children (46\%) under six months of age are exclusively breastfed. Only $20 \%$ children age 6-23 months are fed appropriately according to all threerecommended practices for infant and young child feeding (IYCF) ${ }^{1}$. For this purpose, interventions pertaining to promotion of Infant and Young Child Feeding practices are essential to be scaled up in the country through adequate resource allocation, capacity development and effective communication at all levels of the health system.Improvement in IYCF indicators in the country would require major strengthening of counselling strategies to encourage adoption of appropriate IYCF practices by caregivers. So for this purpose India framed its National Guidelines on Infant and 
Young Child Feeding (IYCF) in 2006 which are a set of well-known, common and scientific recommendations for appropriate feeding of new-born and children under two years. The first two years of life provide a critical window of opportunity for ensuring children's optimal growth and development through adoption of correct infant and child feeding practices. The IYCF practices include the well-known practices of (1) initiating breastfeeding within one hour of birth, (2) exclusive breastfeeding for the first six months (180 days of age) of life, (3) initiation of appropriate complementary feeding from the age of 6 months and (4) continued breastfeeding for two years or beyond.Later on India has also adopted innovations in IYCF such as Mother and Child Protection Card, new WHO growth standards andWorld Breastfeeding Trends Initiative (WBTi)as a system for Tracking, Assessing and Monitoring.

Over the period, there has been a slow but steady increase in early initiation of breastfeeding, especially after launch and operationalization of NRHM. However there has been no improvement in the status of exclusive breast feeding for six months and complementary feeding (6-9 months) ${ }^{1}$.

The adoption of appropriate IYCF practices by the families:

- Reduces the risk of child mortality

- Reduces the risk of preventable infant and childhood illnesses

- Enhances cognitive functions and increases productivity

- Helps in spacing pregnancies as breastfeeding is an effective contraceptive (98.2\%) during the first six months of lactation.

- Reduces burden on health system and costs for societies by protecting against malnutrition (both undernutrition and obesity) and infectious and chronic diseases.

These all are technically very important for India to achieve the targets for Millennium Development Goals (MDG) in 2015.Till now, all these figures we have are based on NFHS -3 (2005-06) $)^{4}$, to assess the present scenario and trends of IYCF practicesin our region, we planned a survey among randomly selected mothers of child below 2 years in 2 districts, one each in Haryana and Punjab. The districts selected were Barnala in Punjab and Kaithal in Haryana having similarities in demographic profiles likeagricultural background, female literacy, 0-6 child sex ratio, Rural -urban population ratios. Moreover, these two states had recently conducted trainings of their health personnel in IYCF practices in collaboration with BPNI in last three years.

\section{Aims \& Objectives}

To assess and compare the present scenario and trends of awareness and practices of IYCF among mothers in Haryana and Punjab.

\section{Methodology}

It was a cross sectional study conducted at State health institutions i.e. General hospitals; after taking permission from the respective incharge of the Hospital/ centre in Barnala and Kaithal. A 22-item, standardized, structured, closed ended questionnaire was developed. It was pretested at Medical College Hospital at Patiala outside the field settings. The questionnaire covered knowledge about breastfeeding and complementary feeding and practices relevant to the mother's experience withher youngest child and problems encountered by themother that reduced the frequency of, or precluded,breastfeeding. It also asked the mother to self-assess her role in feeding.The free and informed consent of the subjects was obtained. Face-to-face interviews were carried out by 2 medical (MBBS) graduates who were well prepared and trained to conduct the interviews in a respectful and courteous way. Total 360 mothers (180 in each district) having child below 2 years were interviewed in a span of 4 months(2014-15) at paediatrics O.P.D. and immunisation sessions at various health care delivery centres and hospitals.

\section{Results}

Table 1 presents the demographic profile of the subjects with respect to age and gender of their child, education, residential and employment status of the subjects (mothers). Noteworthy among these are comparatively higher no. of graduates and working women in the Group A (Kaithal). Similarly there is also higher no. of respondents belonging to urban areas in Group A.

The gap between the knowledge and actual practice of appropriate time for initiation of breastfeedingis evident in Table 2. In group A although $38.89 \%$ of the respondents are aware of the fact that breastfeeding should be initiated in $1^{\text {st }}$ hour of birth but when it comes to practice in their child, this gets reduced to half $(21.11 \%)$. Although the respondents in Group B (Barnala) were found to be having better awareness (61.67\%) but there was again huge gap when it is assessed in terms of actual practice in their child.In general, mothers are having good opinion about colostrum in both the groups but it is definitely higher in Kaithal. It seems to be more due to cultural acceptability of colostrum rather than created awareness. But practice of giving pre-lacteal feed is equally prevalent in both the areas. 
Table 4 presents the gap between the knowledge and practice of exclusive breast feeding of the infant for the first 6 months. While $75 \%$ in Group A and 85\% in Group B were aware about exclusive breastfeeding but during feeding their infants, only around $40 \%$ had actually done this in both the groups. But it was good to find that most of the mothers are of the opinion that breast feeding can be continued during common illness of mother.

The responses regarding attributes of mixed feeding among mothers who have mixed-fed their infants during 0-6 months(Table 5). It shows that most commonly mothers gave other liquids/ water along with breastfeed, followed by giving top milk alongwith. In top milk, Cow's milk is the most preferred choice followed by Buffalo milk. Formula milk was found to be somewhat more preferred in Group A Kaithal (20\%).

Table 6 shows the figures about continuation of breast feeding by mothers having child more than 6 months $(n=68$ and 91$)$. A good no. of mothers i.e. $75 \%$ and $78 \%$ in Group A\& B respectively had actually continued breastfeeding beyond 6 months. Among those who have discontinued, major reasons were inadequate milk secretion, baby not gaining weight, sickness of mother. The responses about duration of breastfeeding by the mothers who had now left breastfeeding their child have also been presented in Table 6. Around 40\% in Group A and around 30\%in Group B had continued breastfeeding beyond 1 year. Regarding age of initiation of complimentary feeding in children who were exclusively breastfed for 6 months, it is apparent that many it was delayed upto 8 month or beyond in majority of the subjects of both the groups. Usage of Bottle to feed the child is found to be higher in Kaithal $(58.6 \%)$ than Barnala $(31.4 \%)$. There was a wide gap in the practice of on demand feeding of the infant during nights by the mother, which could not be explained.

In assessment of role of others (family / health staff) $47 \%$ mothers in Kaithal and $60 \%$ mothers in Barnala stated that they had not been formally counselled, guided or advised by anyone. Role of local health workers although poor in both the groups, but was negligible in Barnala. Regarding help or support from family members, $82 \%$ in Kaithal stated that they did not get any help from family members, they have to do it by themselves; while this situation was better in Barnala.

Lastly, it was perceived important to also assess status of mothers in terms of their own nutrition and their perception regarding their role in feeding their children. Barnala scored better than Kaithal in terms of maternal nutrition where $68.33 \%$ mothers had received both extra nutrition and iron supplements and only 5\% had not received any of them. It was good to see that mothers in both the districts were confident and satisfied about their role in feeding of their children. They were found to be having high morale.

\section{Discussion}

The north Indian states of Punjab \& Haryana are otherwise showing continuousimprovement in their health indicators since the launch of NRHM. Institutional delivery rates are improving in both the states and expected to reach $100 \%$ in near future.Considering the above found trends of IYCF practices collectively in both the districts, it can be concluded that despite of efforts taken to train the health staff by training programs being run by the health departments of both the states for adoption of IYCF practices there was lack of awareness among mothers. Theactual gap between awareness and practice was alsoquite wider. We limit this discussion to only the key practices of IYCF in comparison to established figures of NFHS -3 (2005-06)\& DLHS -3 (2007-08).

Rates of initiation of breastfeeding in $1^{\text {st }}$ hour were $21.11 \%$ in Kaithal and $43.89 \%$ in Barnala in comparison to national figures of $24.5 \%$ in NFHS-3\& $40.2 \%$ in DLHS -3 which were around 9 years back. Although Barnala rates better than Kaithal but such a low rates despite of high institutional delivery rates show neglect of IYCF practices. Moreover around $40 \%$ of the mothers in Kaithal \& $60 \%$ in Barnala are aware of the fact that breastfeeding should be initiated in $1^{\text {st }}$ hour of birth but when it comes to practice in their child, this gets reduced to half. Similar studies in this region in past, have also established deficiencies among mothers regarding awareness. Garg R et al (2010) found that only 13.5\% mothers have put their babies to their breasts in first 4 hours in Amritsar district of Punjab ${ }^{5}$. National fact sheet published by UNICEF after Coverage evaluation survey 2009 also show that only $33.5 \%$ mothers initiate breastfeeding in $1^{\text {st }}$ hour after birth ${ }^{6}$.

Similarly, awareness about exclusive breast feeding for 0-6 months was found to be good (75\% in Kaithal \& $85 \%$ in Barnala) but again practice despite of being aware was poor. It was $39.44 \%$ \& $37.78 \%$ in 2 districts respectively while NFHS-3 and DLHS-3 had an average of $46.4 \%$ of mothers who had exclusively breastfed their infants ${ }^{7}$.NFHS -3 had revealed startling lower EBF rates in Haryana than national average in 2006 also $(16.9 \%)^{8}$. Another study found it to be only $10 \%$ in Panchkula district of Haryana in $2008^{8}$. The poor performance of both the states in above 2 most important indicators should be a point for concern and action. Regarding initiation of complimentary feed; we have found that in most of the subjects who were exclusively breastfed for 6 monthscomplimentary feeding was initiated in $8^{\text {th }}$ month. Less than $30 \%$ initiated it in $7^{\text {th }}$ month. Around $60 \%$ of mothers in both the groups had started mix feeding in first 6 months. The NFHS-3 similarly had suggested that introduction of liquids/ solidsor semi-solid foods often takes place before the recommended age of six months. Almost $30 \%$ of children start receiving complementary food (CF) at the age of 4-5 months. Similarly,delayed CF was also common ${ }^{1}$. 
It was also observed that only around $20 \%$ mothers had continued breastfeeding beyond 18 months. Bottle feeding was found to be more common in Kaithal (58.57\%) which needs to be reduced. Some more findings worth mentioning are at both the areas majority were devoid of any guidance or counselling for breastfeeding and even family support was found deficient by mothers in Kaithal. By now, along with this study NFHS -4 rounds have been completed in 2015 - 2016 in this region and fact sheets have been released. So, it is highly desirable to compare findings with NFHS-4 figures which are shown in Table 8. Surprisingly, the rates of Initiation of breast feeding within $1^{\text {st }}$ hour are in sharp contrast with results of NFHS -4 . This need to be verified by a still large study as NFHS4 result is based on information from only 836 and 838 households in Kaithal and Barnala districts respectively.

\section{Conclusion}

District Barnala scored better than Kaithal in few areas but it is apparent in our findings that there is gap in practicing IYCF practices in those mothers who are aware of them, leaving aside the other respondents who were even not aware. Although both the states are working on the training of health workers to adopt and spread IYCF practices, but still the performance seemsto be even below the national figures shown in NFHS -3 . This study has some limitations because of financial and manpower constraints and was limited to one district coverage in both the states, so results cannot be generalised, but this definitely indicates that despite activities done to improve IYCF practices after 2006, the realistic picture is still gloomy. To establish these trends, wide coverage surveys are required.

\section{Acknowledgements}

We are grateful to the mothers who participated in this study of both the areas, as well as incharge of the public hospitals who permitted us to conduct interviews at the hospitals.

\section{References}

[1]. Guidelines for enhancing optimal Infant and Young Child Feeding practices;Ministry of Health and Family Welfare, Government of India, 2013.

[2]. Vyas S et al; A community based study on breastfeeding practices in a rural area of Uttarakhand. National Journal of Community Medicine Vol 3 Issue 2; 2012, p 282.

[3]. Trends in 3 indicators of Breastfeeding; BPNI. Available at :

a. $\quad$ http://bpni.org/WBW/2012/Trends-3indicators-of-Breastfeeding.pdf[accessed on 14-09-2014]

[4]. WHO Infant and Young Child Feeding: A tool for assessing national practices, policies and programmes. Geneva: WHO; 2003.

[5]. Garg R, Deepti S, Singh T. Study on delivery practices among women in rural Punjab.Health and Population: Perspectives and Issues; Vol. 33 (1), 23-33, 2010.

[6]. National fact sheet- India Coverage Evaluation Survey 2009. Available at : http://www.unicef.org/india/National_Fact_Sheet_CES_2009.pdf [accessed on 12-09-2014]

[7]. India Country Statistics. Available at : http://www.unicef.org/infobycountry/india_statistics.html [accessed on 14-09-2014]

[8]. Kishore S, Kumar P, Aggarwal A. Breastfeeding Knowledge and Practices amongst Mothers in a Rural Population of North India: A Community-based Study. J Trop Pediatr (2009) 55 (3): 183-188.

[9]. NFHS-3 Fact sheet: Haryana. Available at [accessed on 06-06-2017]. http://rchiips.org/NFHS/pdf/Haryana.pdf

[10]. NFHS-3 Fact sheet: Punjab. Available at [accessed on 06-06-2017]. http://rchiips.org/NFHS/pdf/Punjab.pdf

[11]. RN Chaudhary, T Shah, S Raja;Knowledge and practice of mothers regarding breast feeding: a hospital based study. Health Renaissance, Vol 9, No 3 (2011).

[12]. NFHS-4 Fact sheet: Barnala district, Punjab . Available at [accessed on 06-06 2017].http://rchiips.org/NFHS/FCTS/PB/PB_FactSheet_54_Barnala.pdf

[13]. NFHS-4 Fact sheet: Kaithal district, Haryana . Available at [accessed on 06-06-2017].http://rchiips.org/NFHS/FCTS/HR/Kaithal.pdf

\begin{tabular}{|c|c|c|c|}
\hline \multicolumn{4}{|c|}{\begin{tabular}{|l|} 
Table 1. Demographic Profile \\
\end{tabular}} \\
\hline 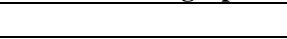 & Group A (Kaithal) $\mathbf{n}=180$ & Group B (Barnala) & $\mathrm{n}=\mathbf{1 8 0}$ \\
\hline \multicolumn{4}{|c|}{ 1. Age distributionof the infant / child } \\
\hline$<6$ months & $112(62.22 \%)$ & $89 \quad(49.44 \%)$ & \\
\hline 6-12 months & $34 \quad(18.88 \%)$ & $37 \quad(20.56 \%)$ & \\
\hline $1-2 \quad$ Years & $34 \quad(18.88 \%)$ & $54 \quad(30.00 \%)$ & \\
\hline \multicolumn{4}{|c|}{ 2. Sex distribution of the infant / child } \\
\hline Male & $103 \quad(57.22 \%)$ & $104 \quad(57.77 \%)$ & \\
\hline Female & $77 \quad(42.78 \%)$ & $76 \quad(42.23 \%)$ & \\
\hline \multicolumn{4}{|c|}{ 3. Educational status of mother } \\
\hline Illiterate & $29 \quad(16.11 \%)$ & $24 \quad(13.33 \%)$ & \\
\hline Literate/ primary school & $24 \quad(13.33 \%)$ & $18 \quad(10.00 \%)$ & \\
\hline Middle school & $23 \quad(12.78 \%)$ & $27 \quad(15.00 \%)$ & \\
\hline High school & $23 \quad(12.78 \%)$ & $54 \quad(30.00 \%)$ & \\
\hline Intermediate & $26 \quad(14.44 \%)$ & $34 \quad(18.89 \%)$ & \\
\hline Graduate & $37 \quad(20.56 \%)$ & $19 \quad(10.56 \%)$ & \\
\hline Postgraduates & $18 \quad(10.00 \%)$ & $(02.22 \%)$ & \\
\hline Professional or Honors & $00 \quad(00.00 \%)$ & $00 \quad(00.00 \%)$ & \\
\hline \multicolumn{4}{|c|}{ 4. Resident of } \\
\hline Urban & $122(67.78 \%)$ & $89 \quad(49.44 \%)$ & \\
\hline
\end{tabular}




\begin{tabular}{|l|ll|ll|}
\hline Rural & $58(32.22 \%)$ & 91 & $(50.56 \%)$ \\
\hline \multicolumn{4}{|c|}{ Employment status of mother } \\
\hline Working & $\mathbf{5 .}$ & 19 & $(10.56 \%)$ \\
\hline Not working ( housewife) & 141 & $(78.33 \%)$ & 161 & $(89.44 \%)$ \\
\hline
\end{tabular}

Table 2. Appropriate time of initiation breast feeding

\begin{tabular}{|l|l|l|}
\hline \multicolumn{3}{|c|}{ Table 2. Appropriate time of initiation breast feeding } \\
\hline \multicolumn{2}{|c|}{ Knowledge about appropriate time for initiation of breast feeding } \\
\hline & Group A (Kaithal) n=180 & Group B (Barnala) n=180 \\
\hline Within 1 hour of birth & $70(38.89 \%)$ & $111(61.67 \%)$ \\
\hline Between 1-4 hours of birth & $91(50.56 \%)$ & $53(29.44 \%)$ \\
\hline Upto3 ${ }^{\text {rd }}$ day of birth & $19(10.56 \%)$ & $16(08.89 \%)$ \\
\hline Upto 1 week of birth & $00(00.00 \%)$ & $00(00.00 \%)$ \\
\hline \multicolumn{2}{|l|}{ B) Actual practice of herself for her child } & $79(43.89 \%)$ \\
\hline Within 1hour of birth & $38(21.11 \%)$ & $43(23.89 \%)$ \\
\hline Between 1-4 hours of birth & $88(48.89 \%)$ & $44(24.44 \%)$ \\
\hline Upto3 ${ }^{\text {dd }}$ day of birth & $38(21.11 \%)$ & $10(05.56 \%)$ \\
\hline Upto 1 week of birth & $11(06.11 \%)$ & $04(02.22 \%)$ \\
\hline Delayed initiation > 1 week & $05(02.78 \%)$ & \\
\hline
\end{tabular}

\begin{tabular}{|c|c|c|}
\hline \multicolumn{3}{|c|}{ Table 3. Colostrum\& Pre-lacteal feed } \\
\hline \multicolumn{3}{|c|}{ A) Opinion regarding colostrum } \\
\hline & Group A (Kaithal) $\mathbf{n = 1 8 0}$ & Group B (Barnala) n=180 \\
\hline Good & $177(98.33 \%)$ & $154(85.56 \%)$ \\
\hline Bad & $03(01.67 \%)$ & $26(14.44 \%)$ \\
\hline \multicolumn{3}{|c|}{ B) Pre-lacteal Feeds } \\
\hline Given & $84 \quad(46.67 \%)$ & $98 \quad(54.44 \%)$ \\
\hline Not given & $96 \quad(53.33 \%)$ & $82(45.56 \%)$ \\
\hline
\end{tabular}

\begin{tabular}{|c|c|c|}
\hline \multicolumn{3}{|c|}{ Table 4. Exclusive Breast feeding for initial 6 months } \\
\hline \multicolumn{3}{|c|}{ A) Knowledge / Awareness } \\
\hline & Group A (Kaithal) $\mathbf{n}=180$ & Group B (Barnala) $n=180$ \\
\hline Exclusive breast feeding & $135(75.00 \%)$ & $154(85.56 \%)$ \\
\hline Mixed feeding & $45 \quad(25.00 \%)$ & $(14.44 \%)$ \\
\hline \multicolumn{3}{|c|}{ B) Actual practice of herself for her child } \\
\hline Exclusive breast feeding & $71 \quad(39.44 \%)$ & $(37.78 \%)$ \\
\hline Mixed feeding & $109(60.56 \%)$ & $(62.22 \%)$ \\
\hline \multicolumn{3}{|c|}{ C) Opinion regarding Breastfeeding during illness of mother } \\
\hline Continued & $175(97.22 \%)$ & $174(96.67 \%)$ \\
\hline Discontinued & $05(02.78 \%)$ & $06(03.33 \%)$ \\
\hline
\end{tabular}

\begin{tabular}{|c|c|c|}
\hline \multicolumn{3}{|c|}{ Table 5. Attributes of Mixed feeding in 0-6 months } \\
\hline & Group A (Kaithal) n= 109 & Group B (Barnala) n= 112 \\
\hline \multicolumn{3}{|l|}{ A) Other substances } \\
\hline Breast milk + other top milk & $34(31.19 \%)$ & $41(36.61 \%)$ \\
\hline $\begin{array}{l}\text { Breast milk }+ \text { water/ other } \\
\text { fluids }\end{array}$ & $70(64.22 \%)$ & $55(49.10 \%)$ \\
\hline Breast milk + other solids & $05(04.58 \%)$ & $16(14.29 \%)$ \\
\hline \multicolumn{3}{|c|}{ B) Top milk used during mixed feeding } \\
\hline & Group A (Kaithal) n=34 & Group B (Barnala) $n=41$ \\
\hline Packaged milk & $00(00.00 \%)$ & $00(00.00 \%)$ \\
\hline Goat's milk & $01(02.94 \%)$ & $00(00.00 \%)$ \\
\hline Cow's milk & $15(44.12 \%)$ & $27(65.85 \%)$ \\
\hline Formula's milk & $07(20.59 \%)$ & $03(07.32 \%)$ \\
\hline Buffalo's milk & $11(32.35 \%)$ & $11(26.83 \%)$ \\
\hline
\end{tabular}

\begin{tabular}{|c|c|c|}
\hline \multicolumn{3}{|c|}{ Table 6. Breast feeding beyond 6 months } \\
\hline \multicolumn{3}{|c|}{ Continuation of breast feeding beyond $6 \mathrm{n}$} \\
\hline & Group A (Kaithal) $n=68$ & Group B (Barnala) n=91 \\
\hline Continued & $51(75.00 \%)$ & $71(78.02 \%)$ \\
\hline Discontinued & $17(25.00 \%)$ & $20(21.98 \%)$ \\
\hline \multicolumn{3}{|c|}{ B) Prime reason for discontinuing breast feeding } \\
\hline & Group A (Kaithal) n= 17 & Group B (Barnala) $\mathbf{n}=\mathbf{2 0}$ \\
\hline Inadequate milk secretion & $11(64.71 \%)$ & $16(80.00 . \%)$ \\
\hline Not sucking well on breast & $00(00.00 \%)$ & $00(00.00 \%)$ \\
\hline
\end{tabular}


A Comparative Study of Infant And Young Child Feeding Practices In one District Each ...

\begin{tabular}{|c|c|c|c|c|}
\hline Baby not gaining weight & \multicolumn{2}{|l|}{$02(11.76 \%)$} & \multicolumn{2}{|l|}{$02(10.00 \%)$} \\
\hline Mother got pregnant & \multicolumn{2}{|l|}{$01(5.88 \%)$} & \multicolumn{2}{|l|}{$00(00.00 \%)$} \\
\hline Breast abscess/ sore nipple & \multicolumn{2}{|l|}{$00(00.00 \%)$} & \multicolumn{2}{|l|}{$00(00.00 \%)$} \\
\hline Baby became sick & \multicolumn{2}{|l|}{$01(5.88 \%)$} & \multicolumn{2}{|l|}{$01(05.00 \%)$} \\
\hline Mother became sick & \multicolumn{2}{|l|}{$02(11.76 \%)$} & \multicolumn{2}{|l|}{$01(05.00 \%)$} \\
\hline \multicolumn{5}{|c|}{ C) Duration of breast feeding in mothers who have now left breastfeeding their child } \\
\hline & \multicolumn{2}{|c|}{ Group A (Kaithal) n=26 } & \multicolumn{2}{|c|}{ Group B (Barnala) $n=38$} \\
\hline$<=6$ months & \multicolumn{2}{|l|}{$09(34.61 \%)$} & \multicolumn{2}{|l|}{$18(47.37 \%)$} \\
\hline $6-12$ months & \multicolumn{2}{|l|}{$06(23.08 \%)$} & \multicolumn{2}{|l|}{$08(21.05 \%)$} \\
\hline $12-18$ months & \multicolumn{2}{|l|}{$06(23.08 \%)$} & \multicolumn{2}{|l|}{$04(10.53 \%)$} \\
\hline $18-24$ months & \multicolumn{2}{|l|}{$05(19.23 \%)$} & \multicolumn{2}{|l|}{$08(21.05 \%)$} \\
\hline & imentary feed & in children $w$ & were exclusi & breastfed for 6 \\
\hline & \multicolumn{2}{|c|}{ Group A (Kaithal) $n=34$} & \multicolumn{2}{|c|}{ Group B (Barnala) n= 37} \\
\hline $7^{\text {th }}$ month & \multicolumn{2}{|l|}{$8 \quad(23.53 \%)$} & \multicolumn{2}{|l|}{$11(29.73 \%)$} \\
\hline $8^{\text {th }}$ month & \multicolumn{2}{|l|}{$18 \quad(52.94 \%)$} & \multicolumn{2}{|l|}{$22(59.46 \%)$} \\
\hline$>8$ months & \multicolumn{2}{|l|}{$8 \quad(23.53 \%)$} & \multicolumn{2}{|l|}{$04(10.81 \%)$} \\
\hline \multicolumn{5}{|c|}{ E) Attributes of complimentary feeding } \\
\hline & \multicolumn{2}{|c|}{ Group A (Kaithal) $n=70$} & \multicolumn{2}{|c|}{ Group B (Barnala) n= 86} \\
\hline & Yes & No & Yes & No \\
\hline Bottle feeding & $41(58.57 \%)$ & $29(41.43 \%)$ & $27(31.40 \%)$ & $59(68.60 \%)$ \\
\hline Spoon feeding & $37(52.86 \%)$ & $33(47.14 \%)$ & $55(63.95 \%)$ & $31(36.04 \%)$ \\
\hline On demand feeding during night & $18(25.71 \%)$ & $52(74.29 \%)$ & $83(96.51 \%)$ & $03(03.49 \%)$ \\
\hline
\end{tabular}

\begin{tabular}{|c|c|c|}
\hline \multicolumn{3}{|l|}{ A) Counselled/Advised/ Guided by someone } \\
\hline & $\begin{array}{l}\text { Group A (Kaithal) } \\
n=180\end{array}$ & $\begin{array}{l}\text { Group B (Barnala) } \\
n=180\end{array}$ \\
\hline Doctor & $31(17.22 \%)$ & $62(34.44 \%)$ \\
\hline Relative & $20(11.11 \%)$ & $05(02.78 \%)$ \\
\hline Local health worker & $44(24.44 \%)$ & $04(02.22 \%)$ \\
\hline Not counselled & $85(47.22 \%)$ & $109(60.56 \%)$ \\
\hline \multicolumn{3}{|l|}{ B) Aid/Support in feeding } \\
\hline Father & $03 \quad(01.67 \%)$ & $26 \quad(14.44 \%)$ \\
\hline Grandmother & $27 \quad(15.00 \%)$ & $88 \quad(48.89 \%)$ \\
\hline Others & $02 \quad(01.11 \%)$ & $34 \quad(18.89 \%)$ \\
\hline No help & $148 \quad(82.22 \%)$ & $32 \quad(17.78 \%)$ \\
\hline \multicolumn{3}{|l|}{ C) Maternal nutrition } \\
\hline $\begin{array}{l}\text { Takenonly extra food (calories) during pregnancy } \\
\text { and lactation }\end{array}$ & $19(10.56 \%)$ & $13(07.22 \%)$ \\
\hline $\begin{array}{l}\text { Taken only Iron + Folic acid supplements during } \\
\text { pregnancy and lactation }\end{array}$ & $38(21.11 \%)$ & $35(19.44 \%)$ \\
\hline Both & $107(59.44 \%)$ & $123(68.33 \%)$ \\
\hline None & $16(08.89 \%)$ & $09 \quad(05.00 \%)$ \\
\hline \multicolumn{3}{|c|}{ D) Self-assessment by mothers of their role in child feeding } \\
\hline Completely satisfied & $138(76.67 \%)$ & $147(81.67 \%)$ \\
\hline Partly satisfied & $40 \quad(22.22 \%)$ & $(15.56 \%)$ \\
\hline Not satisfied & $02(01.11 \%)$ & $05(02.78 \%)$ \\
\hline
\end{tabular}

\begin{tabular}{|l|l|l|l|l|}
\hline Table 8 : Comparison with NFHS - 4 & \multicolumn{3}{|l|}{$\mid$} \\
\hline Parameter & & $\begin{array}{l}\text { Present study } \\
(2014-15)\end{array}$ & $\begin{array}{l}\text { NFHS -4 } \\
(2015-16)\end{array}$ & $\begin{array}{l}\text { NFHS -3 } \\
(2005-06)\end{array}$ \\
\hline $\begin{array}{l}\text { Children under age 3 years breastfed } \\
\text { within one hour of birth }\end{array}$ & Barnala & $43.89 \%$ & $34.4 \%$ & $10.3 \%$ (Punjab) \\
\cline { 2 - 6 } & Kaithal & $21.11 \%$ & $49.7 \%$ & $\begin{array}{l}22.3 \\
\text { (Haryana) }\end{array}$ \\
\hline $\begin{array}{l}\text { Children under age 6 months } \\
\text { exclusively breastfed }\end{array}$ & Barnala & $37.78 \%$ & - NA- & $36.0 \%$ (Punjab) \\
\cline { 2 - 5 } & Kaithal & $39.44 \%$ & $41.1 \%$ & $\begin{array}{l}16.9 \\
\text { (Haryana) }\end{array}$ \\
\hline
\end{tabular}

